\title{
Stable isotope data and FTIR analyses of diamonds from Orapa Mine: a clear subduction signature
}

\author{
Ingrid L. Chinn ${ }^{1}$, Samantha H. Perritt ${ }^{1}$, Johann Stiefenhofer ${ }^{2}$ and Richard A. Stern ${ }^{3}$ \\ ${ }^{1}$ De Beers Exploration, Johannesburg, South Africa, ingrid.chinn@debeersgroup.com, \\ samantha.perritt@debeersgroup.com \\ ${ }^{2}$ MinRes, Anglo American Operations Ltd, Johannesburg, South Africa, \\ johann.stiefenhofer@debeersgroup.com \\ ${ }^{3}$ University of Alberta,Edmonton, rstern@ualberta.ca
}

\section{Introduction}

Colour, morphology and Fourier transform infrared (FTIR) data were acquired for over 2000 diamonds from Orapa Mine. The diamonds span a large range in maximum dimension from 0.15-4.75 $\mathrm{mm}$. A subset of 198 diamonds covering the range in colour, morphology, nitrogen content and aggregation state was analysed by secondary-ion mass spectrometry (SIMS) to acquire nitrogen abundance and carbon and nitrogen isotope data. Previous work on inclusion-bearing diamonds from Orapa has highlighted the importance of the eclogitic and websteritic parageneses (Deines et al. 1993), with the latter being characterised by diamonds stongly depleted in ${ }^{13} \mathrm{C}$.

\section{Analytical Methods}

Transmission FTIR analyses were conducted on whole stones using a Bruker Vertex 70 spectrometer with Hyperion 2000 microscope from 7500 to $370 \mathrm{~cm}^{-1}$ at a resolution of $4 \mathrm{~cm}^{-1}$. Spectra were baselined manually and processed using an automated Microsoft Excel program based on a program written by D Fisher (De Beers Technologies UK). SIMS analyses were conducted at the Canadian Centre for Isotopic Microanalysis, University of Alberta. Details of analytical conditions and reference materials may be found in Stern et al. (2014) and Hogberg et al. (2016).

\section{Results}

Individual diamonds show considerable heterogeneity in nitrogen content and aggregation state, and carbon and nitrogen isotopic composition. Generally, stones that show significant heterogeneity in isotopic composition and/or nitrogen abundance show clear evidence of more than one distinct growth event in cathodoluminescence (CL) images (e.g. Figure 1). In some instances truncation of growth zonation indicates the presence of a resorption boundary associated with a diamond destruction event. Some diamonds appear to show evidence of multiple growth and/or resorption events.

\begin{tabular}{|l|r|r|r|r|}
\hline Analysis & $\mathrm{N}(\mathrm{ppm})$ & $\delta^{13} \mathrm{C}(\% 0)$ & $\delta^{15} \mathrm{~N}(\% 0)$ \\
\hline Point & & 219 & -8.7 & +12.1 \\
\hline 1 & 1140 & -8.7 & +12.0 \\
\hline 2 & 1162 & -9.9 & +7.3 \\
\hline 3 & 32 & -11.6 & n.a. \\
\hline 4 & 272 & -11.7 & +15.4 \\
\hline 5 & & & \\
\hline
\end{tabular}

Figure 1: CL image of an Orapa diamond with complex zonation indicative of multiple growth events and at least two resorption boundaries. Locations of SIMS analyses and matching data are shown in the adjacent table. 
The range in carbon isotope $\left(\delta^{13} \mathrm{C}_{\mathrm{VPDB}}\right)$ composition for the diamonds analysed is from -28.6 to -2.1 $\%$ and the maximum variation recorded for an individual diamond is $18.0 \%$ : from $-24.2 \% 0$ (core) to $-6.2 \%$ (rim). The overall range in nitrogen isotope $\left(\delta^{15} \mathrm{~N}_{\text {AIR }}\right)$ composition is from -10.4 to $+23.0 \%$ and the maximum variation in a single diamond is $14.7 \%$, from -2.8 to $+11.9 \%$. The largest variation in nitrogen content in a single diamond is 3577 atomic ppm, from below 11 to 3588 atomic ppm, where the latter value is the highest nitrogen content recorded by SIMS for these analyses.

Some diamonds with relatively simple zonation (e.g. Figure 2) show a change from cores depleted in ${ }^{13} \mathrm{C}$, with high nitrogen contents and positive $\delta^{15} \mathrm{~N}$ values, to rims with "mantle" $\delta^{13} \mathrm{C}$ values (Cartigny 2005), moderately high nitrogen contents and negative $\delta^{15} \mathrm{~N}$ values. The reverse trend is also recognised, consistent with the presence of several growth events recorded by the diamond populations of Orapa.

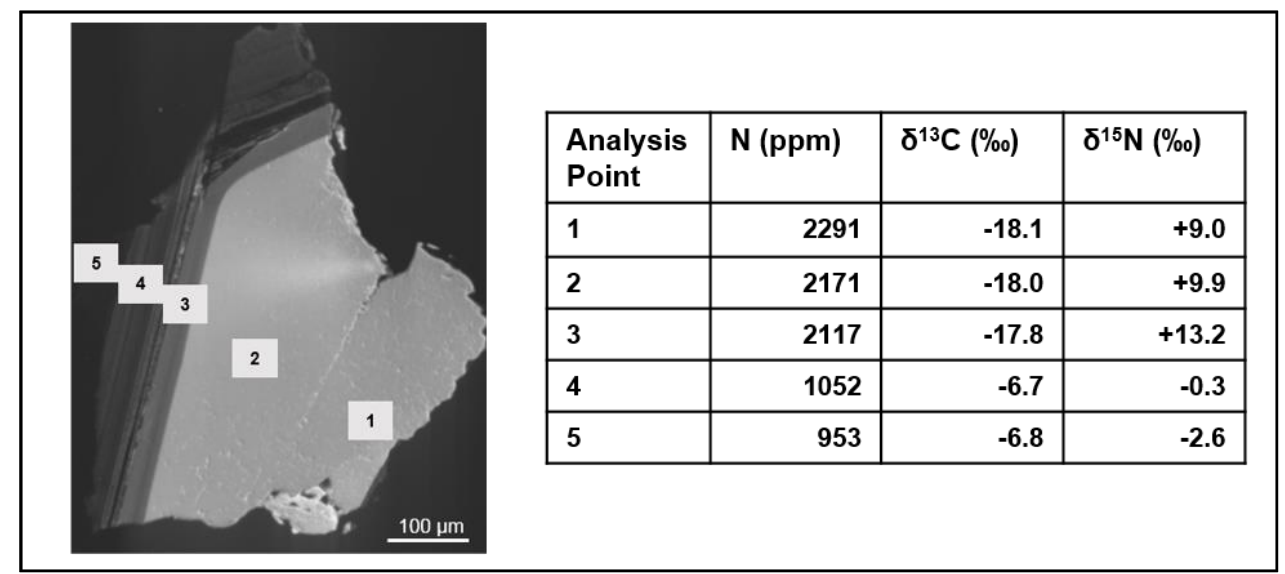

Figure 2: CL image of an Orapa diamond with simple zonation with "mantle" values of $\delta^{13} \mathrm{C}, \delta^{15} \mathrm{~N}$ and nitrogen content in the rim. Locations of SIMS analyses and matching data are shown in the adjacent table.

A "mantle" signature is seen in a group of diamonds with restricted $\delta^{13} \mathrm{C}$ values from -8 to $-2 \%$, $\delta^{15} \mathrm{~N}$ values from -5 to $+5 \%$, and nitrogen contents of $\sim 600$ to $1800 \mathrm{ppm}$. The carbon isotope compositions of this group correspond to one of the two modes recognised for Orapa inclusion-bearing diamonds by Deines et al. (1993). They reported a well-defined mode between -15 and $-13 \%$ for eclogitic diamonds. In the current data this mode is shifted to lower values between -20 and $-18 \%$.

A plot of nitrogen content versus $\delta^{13} \mathrm{C}$ (Figure 3) shows a significant proportion (22\%) of the 508 coupled SIMS analyses displaying strongly negative $\delta^{13} \mathrm{C}$ values and high nitrogen contents, falling well outside the limit sector curve defined for diamonds worldwide (Cartigny et al. 2001). The anomalous diamonds are also characterised by positive $\delta^{15} \mathrm{~N}$ values (Figure 3) consistent with a crustal/sedimentary derivation (Thomazo et al. 2009). A few similar anomalous diamonds have been reported previously (Hogberg et al. 2016 and references therein) including a diamondite from Orapa and websteritic diamondites from unknown southern African sources (Mikhail et al. 2014).

\section{Discussion}

Given the extreme heterogeneity in isotopic compositions and nitrogen content recorded in individual diamonds and supported by CL images, the need for detailed and spatially controlled stable isotopic analyses of representative samples is clearly demonstrated if the complex origins of diamonds such as these from Orapa are to be fully understood. Diamond growth complexity must also be taken into account when isotopic ratios of inclusions are used to generate diamond growth ages, as a large proportion of diamonds clearly grew episodically, and in some cases over an extended period of time, e.g. $2 \mathrm{Ga}$, (Timmerman et al. 2017). Unfortunately, most diamonds for which carbon isotope data have been published are inclusion-bearing, and in isotopic composition are not necessarily representative of the run-of-mine populations, resulting in a bias that has missed the presence of the subduction isotopic signature recognised here. Whole stone FTIR analyses and bulk isotopic analyses 
which form the bulk of global diamond analyses are likely to have resulted in average isotopic values and nitrogen contents that precluded recognition of diamonds that grew from subducted sedimentary material. The data presented here show that diamonds reflecting sedimentary subduction signatures in terms of both carbon and nitrogen isotopic compositions can comprise a significant proportion of the diamond populations at an operational mine, highlighting the economic importance of subduction and the global carbon cycle.

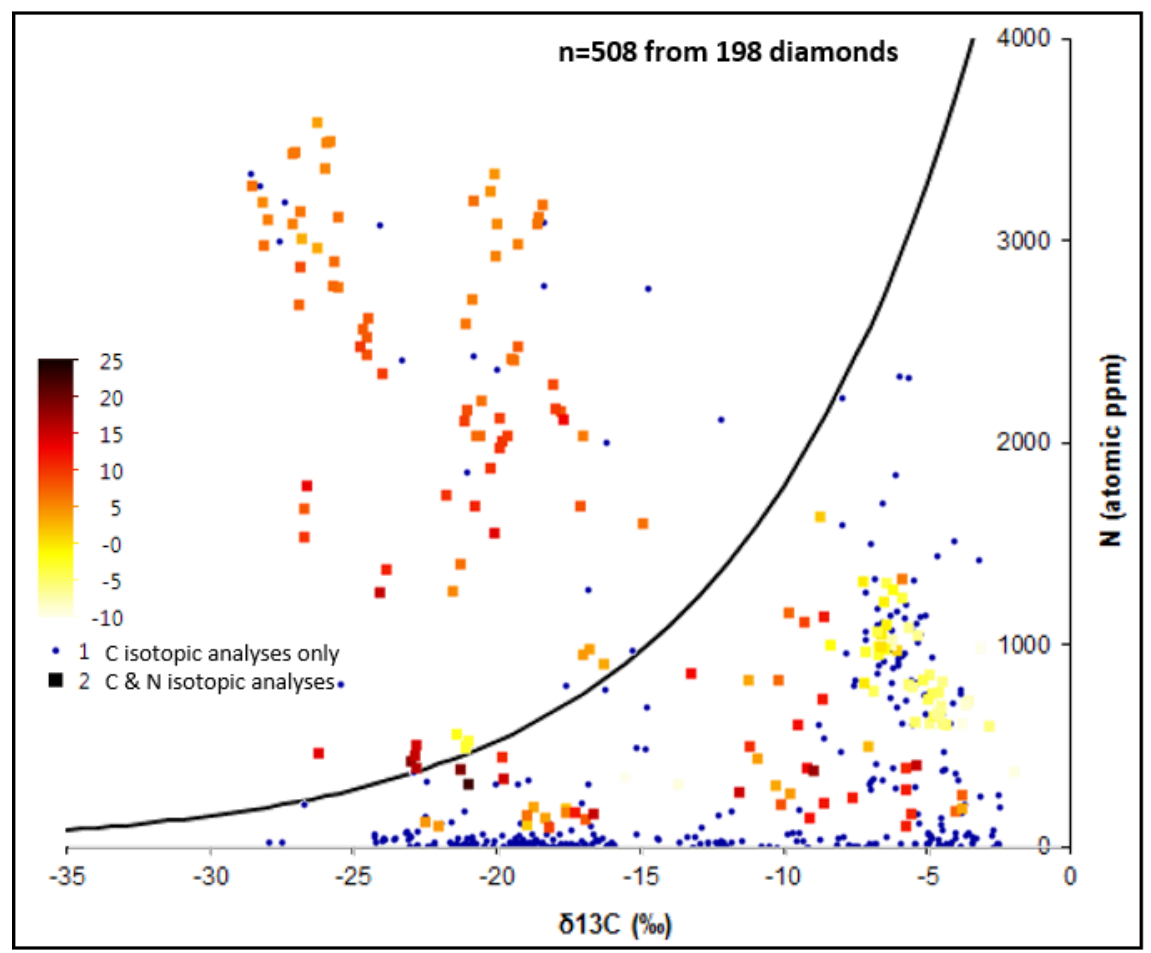

Figure 3: Nitrogen content versus carbon isotopic composition for Orapa diamonds. Selected SIMS analyses for which there was sufficient nitrogen to obtain nitrogen isotopic compositions (large symbols) are colour coded for $\delta^{15} \mathrm{~N}$ values as per the legend. The black line represents the limit sector curve of Cartigny et al. (2001).

\section{References}

Cartigny P, Harris JW, Javoy M (2001) Diamond genesis, mantle fractionations and mantle nitrogen content: a study of $\delta^{13} \mathrm{C}-\mathrm{N}$ concentrations in diamonds. Earth Planet. Sci. Lett. 185:85-98

Cartigny P (2005) Stable Isotopes and the Origin of Diamond. Elements 1:79-84

Deines P, Harris JW, Gurney JJ (1993) Depth-related carbon isotope and nitrogen concentration variability in the mantle below the Orapa kimberlite, Botswana, Africa. Geochim. Cosmoschim. Acta 57:2781-2796

Hogberg K, Stachel, T, Stern RA (2016) Carbon and nitrogen isotope systematics in diamond: Different sensitivities to isotopic fractionation or a decoupled origin? Lithos 265:16-30

Mikhail S, Verchovsky AB, Howell D, Hutchinson MT, Southworth R, Thomson AR, Warburton P, Jones AP, Milledge HJ (2014) Constraining the internal variability of the stable isotopes of carbon and nitrogen within mantle diamonds. Chem. Geol. 366:14-23

Stern RA, Palot M, Howell D, Stachel T, Pearson DG, Cartigny P, Oh A. (2014) Methods and reference materials for SIMS diamond $\mathrm{C}$ - and $\mathrm{N}$-isotope analysis. Canadian Centre for Isotopic Microanalysis, Research Report 14-01. University of Alberta, Education and Research Archive. http://hdl.handle.net/10402/era.38738.

Thomazo C, Pinti DI, Busigny V, Ader M, Hashizume K, Philippot P (2009) Biological activity and the Earth's surface evolution: Insights from carbon, sulfur, nitrogen and iron stable isotopes in the rock record. C. R. Palevol 8:665-678

Timmerman S, Koornneef JM, Chinn IL, Davies GR (2017) Dated eclogitic diamond growth zones reveal variable recycling of crustal carbon through time. Earth Planet. Sci. Lett. 463:178-188 